\title{
The OmniPod Insulin Management System: the Latest Innovation in Insulin Pump Therapy
}

\author{
Howard C. Zisser
}

Received: August 6, 2010 / Published online: September 13, 2010

(c) The Author(s) 2010. This article is published with open access at Springerlink.com

\section{ABSTRACT}

This review of insulin pump therapy focuses on the OmniPod ${ }^{\circledR}$ Insulin Management System (Insulet Corp., Bedford, MA, USA). The OmniPod System is the first commercially available "patch pump." It is a fully integrated wearable pump, controlled wirelessly through a handheld device containing a built-in blood glucose meter. This is an evaluation of the OmniPod System, with the aim of providing an educational tool for physicians who are considering recommending this product to their patients. The review includes a discussion of the traditional insulin pump configuration and its limitations, a detailed overview of the OmniPod System, references to clinical study data, planned product enhancements, its use as an insulin delivery system in the Juvenile Diabetes Research Foundation's Artificial Pancreas Project, and its use to deliver additional compounds.

Howard C. Zisser ( $\square)$

Director of Clinical Research and Diabetes Technology,

Sansum Diabetes Research Institute

Adjunct Professor, Department of Chemical

Engineering, University of California/Santa Barbara,

2219 Bath Street, Santa Barbara, CA 93105, USA.

Email: hzisser@sansum.org
Keywords: continuous glucose monitor; continuous subcutaneous insulin infusion; insulin pump; multiple daily injections; patch pump; wireless pump

\section{INTRODUCTION}

This review is intended to provide an educational tool for physicians who want to recommend an insulin pump to their patients and need to learn about the current technologies available to them. The review focuses on the OmniPod $^{\circledR}$ Insulin Management System (Insulet Corp., Bedford, MA, USA), comparing it to traditional insulin pumps and explaining its value within the range of products.

\section{Traditional Insulin Pump Therapy}

Insulin pumps were first developed for commercial use in the late 1970s. Over the past 30 years, the components have changed little. The components of traditional pump systems used for diabetes management include:

- A device about the size of a deck of cards that contains an insulin reservoir, a pumping mechanism, batteries, and a microchip that carries the user's daily insulin delivery 
programs and delivery history. The device has a screen and buttons to aid the user in delivering the proper amount of insulin. Current pumps come with color screens, sleek outlines, and much-improved user interface. The patient usually wears the device in a pocket or hooked on a belt or waistband.

- An infusion set that attaches to the patient's skin with adhesive and includes a short plastic cannula that is inserted just beneath the skin to allow access for the insulin. The patient either uses a mechanical inserter to attach the set and insert the cannula, or inserts the infusion set by hand.

- A length of tubing that delivers the insulin from the pump to the infusion set and cannula. Tubing ranges from 30 to $110 \mathrm{~cm}$ (11.8 to 43.3 inches).

- A separate blood glucose (BG) monitor. The patient uses the result on the monitor to calculate the dosage of insulin s/he should take and then inputs that instruction to the pump. Most pumps also include a bolus

Table 1. Insulin pump (continuous subcutaneous insulin infusion) products currently available.

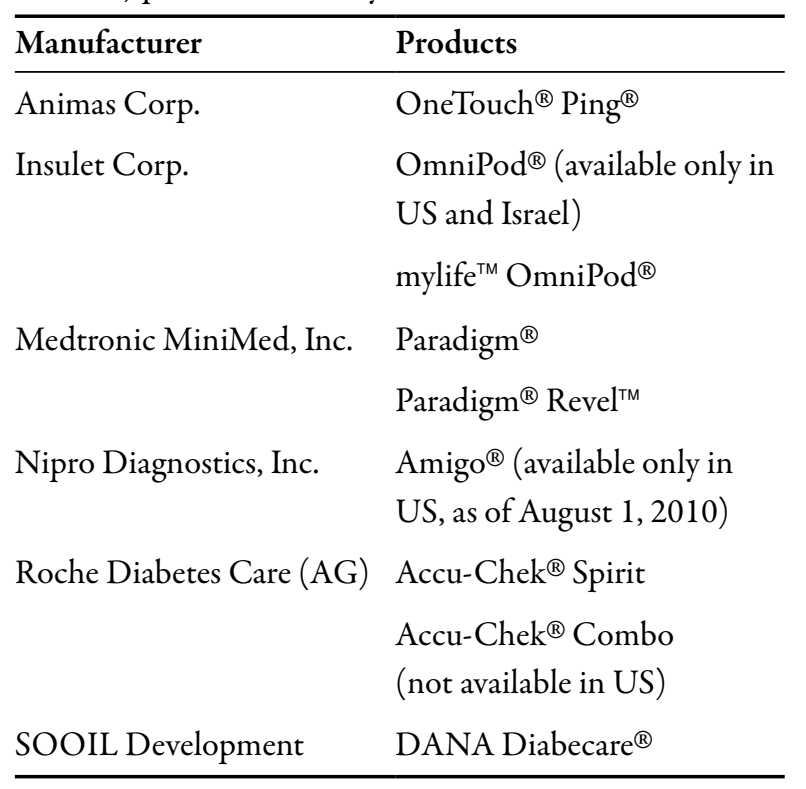

calculator to assist with these calculations. (In recent years, more pumps have added linked glucose meters that convey the BG value to the pump for correction bolus calculations.)

Table 1 lists insulin pump products currently available, alphabetically by manufacturer.

\section{Benefits of Insulin Pump Therapy}

Patients using multiple daily injections (MDI) typically inject four times a day or more, usually using two different types of insulin. The appeal of insulin pumps has been that they eliminate the need for these injections while allowing for greater customization and tailoring of insulin delivery. Insurers recognize the benefits to certain patients; for example, to get reimbursement for insulin pump therapy in the $\mathrm{EU}$, the patient must have one or more of these indications:

- Dawn phenomenon

- Severe hypoglycemia unawareness

- An irregular daily schedule, such as people who work various shifts or have unforeseen physical activities requiring a reduction of basal insulin

- Pregnancy

- Diabetes complications that require very tight glucose control.

Continuous subcutaneous insulin infusion (CSII) therapy is not limited to those populations. It can benefit any patient with type 1 diabetes. Use of an insulin pump frees the patient from the strict eating schedule required when using long- and intermediate-acting insulins, and allows increased flexibility in daily activities. While the basal (or background) dosage is preprogrammed, it can be changed as needed. Meal and correction boluses are given as needed during the course of the day. So, for example, if the patient has no appetite for breakfast, s/he can replace it with a small snack or nothing, 
checking periodically that the BG remains steady. Further, if the patient wants to exercise at any given time, $\mathrm{s} /$ he can reduce or halt the basal delivery for a specified time, add food intake, reduce the bolus prior to exercise, or all three, as needed-all while checking the BG periodically.

\section{Limitations of Traditional Insulin Pump Therapy}

While pumping is freeing in some respects, it is also an added responsibility. Because pumps use rapid-acting insulin analogs, any interruption in insulin delivery may result in hyperglycemia and the rapid onset of diabetic ketoacidosis. In addition, traditionally designed systems have a number of limitations that could be improved upon to allow more patients with diabetes to benefit from CSII therapy. These include:

- Long tubing connects the insulin reservoir in a traditional pump to the infusion set. The tubing has to be managed by patients in all aspects of daily living (dressing, exercising, etc). This tubing can catch on things during daily use, resulting in disruption of insulin delivery.

- The process of inserting the cannula with mechanical inserters or by hand is awkward and can result in variable cannula insertion angles and depths. This mechanical or manual cannula insertion process can be intimidating to some patients.

- Managing the large number of components required during setup and infusion set changes is complex.

- Locations to insert infusion sets are relatively limited.

These limitations left room for innovation and improvement, which the designers of the OmniPod Insulin Management System implemented in their design and development, described in detail in the next section.
Table 2. Design awards won by the OmniPod Insulin Management System.

\begin{tabular}{ll}
\hline Year & Award \\
\hline 2006 & $\begin{array}{l}\text { Gold Industrial Design Excellence Award (IDEA) } \\
\text { from the Industrial Designers Society of America }\end{array}$ \\
2006 & $\begin{array}{l}\text { Medical Design Excellence Award (MDEA) } \\
\text { for General Hospital Devices and Therapeutic } \\
\text { Products }\end{array}$ \\
2009 & $\begin{array}{l}\text { Edison Best New Product Award } \\
\text { and } \text { in the Science }\end{array}$ \\
\hline
\end{tabular}

\section{THE OMNIPOD SYSTEM: WHAT IS IT AND HOW DOES IT WORK?}

Insulin pumps are not all the same. Physicians and their patients need to choose a pump to fit the individual's needs and lifestyle. The OmniPod System is quite innovative in resolving the limitations of traditional pumps listed above.

The OmniPod Insulin Management System is a novel insulin pump system designed by Insulet Corporation. The company was founded in 2000. In mid-2003, Insulet received its first 501(k) clearance from the Food and Drug Administration (FDA) for the OmniPod System. In early 2005, the commercial version of the OmniPod System was cleared by the FDA, and the product was shipped to the first patient later that year. By the end of 2008, the System was available and supported in all 50 US states. As of July 2010, the System is available in the United Kingdom and Germany under the brand mylife ${ }^{\mathrm{TM}} \mathrm{OmniPod}^{\circledR}$, and will soon be launched in other EU countries along with Australia and China.

The OmniPod System has won three awards for innovation in both industrial design and medical technology design (see Table 2). These honors demonstrate that those in the larger medical area (but not directly concerned with 
Figure 1. OmniPod Insulin Management System.

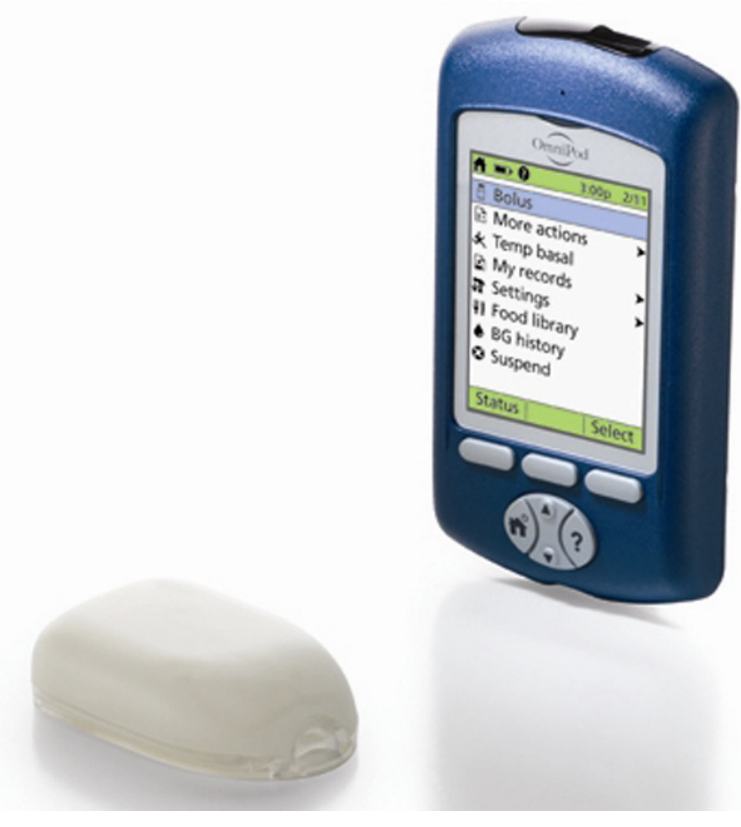

diabetes) are also convinced that this device is a real improvement in therapy.

\section{System Components}

The Insulet OmniPod Insulin Management System is comprised of two components (Figure 1): the OmniPod Disposable Infusion Pump (Pod) and the OmniPod Personal Diabetes Manager (PDM), which incorporates the FreeStyle $^{\circledR}$ (Abbott Diabetes Care, Alameda, CA, USA) BG meter.

The PDM is a hand-held, battery-powered remote controller for the Pod (insulin pump). It has seven functional buttons, a back-lit liquidcrystal colored display, and a BG meter. The PDM provides audio alarms, alerts, and reminders related to insulin delivery, reservoir level, Pod functioning, and battery life.

The Pod is activated and controlled exclusively through use of the PDM. The Pod and PDM interact wirelessly using secure, bidirectional radio frequency. Wireless interaction is only required to set a bolus delivery, change system settings, perform BG measurements, or change the Pod; in operation mode and during basal delivery, no wireless connection is needed, so the PDM does not need to be near the Pod. The Pod sounds an alarm if any attention is needed.

The Pod is a microprocessor-controlled device worn directly on the body. It delivers insulin based on the user's custom-programmed basal rates and bolus doses for up to 3 days according to patient's individual insulin needs.

\section{Contraindications}

Similar to traditional insulin pumps, the OmniPod is not recommended for people who are:

- Unable to perform at least four BG tests per day

- Unable to maintain contact with their healthcare provider

- Unable to use the system according to instructions.

The integrated BG meter is not to be used for:

- Testing newborns

- Testing arterial blood

- Diagnosing diabetes.

\section{Detailed Product Description}

\section{The Pod}

The Pod is a single-use disposable device. It is small, lightweight, and worn directly on the body. The adhesive on the base of the Pod keeps it securely in place for up to 3 days. The Pod incorporates a piezo ceramic resonator to provide audio alarms, alerts, and reminders.

Insulin is delivered through an integrated soft cannula in the Pod that is inserted automatically into the subcutaneous tissue. 
Figure 2. Schematic of the OmniPod motor mechanism, featuring shape memory alloy (SMA) wire.

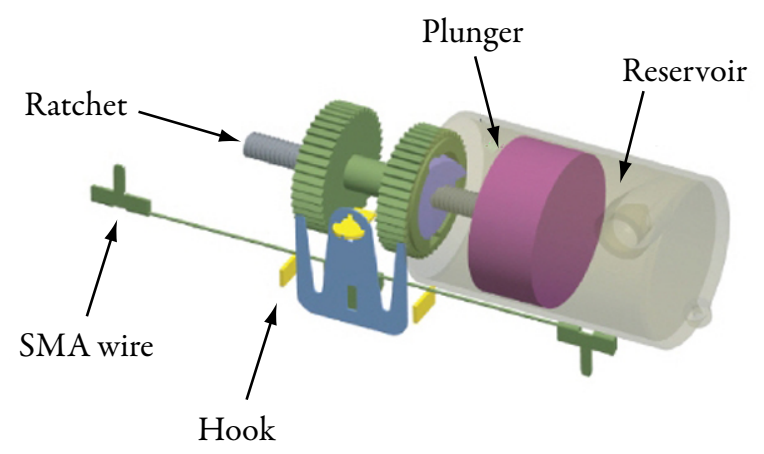

The cannula is inserted in five 1000ths of a second. The Pod is intended for use with rapidacting U-100 insulin: NovoLog ${ }^{\circledR}$ (Novo Nordisk A/S, Copenhagen, Denmark), NovoRapid ${ }^{\circledR}$ (Novo Nordisk A/S), Humalog ${ }^{\circledR}$ (Eli Lilly, Indianapolis, IA, USA), or Apidra ${ }^{\circledR}$ (SanofiAventis, Paris, France).

The pad on the base of the Pod uses a standard, commercially available, medicalgrade adhesive, designed for one-time use. Once removed, a Pod cannot be reapplied.

The Pod is watertight at a depth of 25 feet for up to 60 minutes (IPX8). Its housing includes a viewing window at the infusion site, which allows the patient to inspect the insertion site for proper cannula placement and integrity. The Pod also includes a vent to ensure pressure equilibration with the surrounding environment. The housing does not have any elements that allow user access to the pump mechanism or electronics and it contains no user-serviceable parts.

\section{Pod Motor Mechanism}

The motor mechanism of the Pod incorporates microprocessor control, shape memory alloy (SMA) wire assembly (Figure 2), step sensor, and
Figure 3. A look under the hood, featuring core components of the OnmiPod.

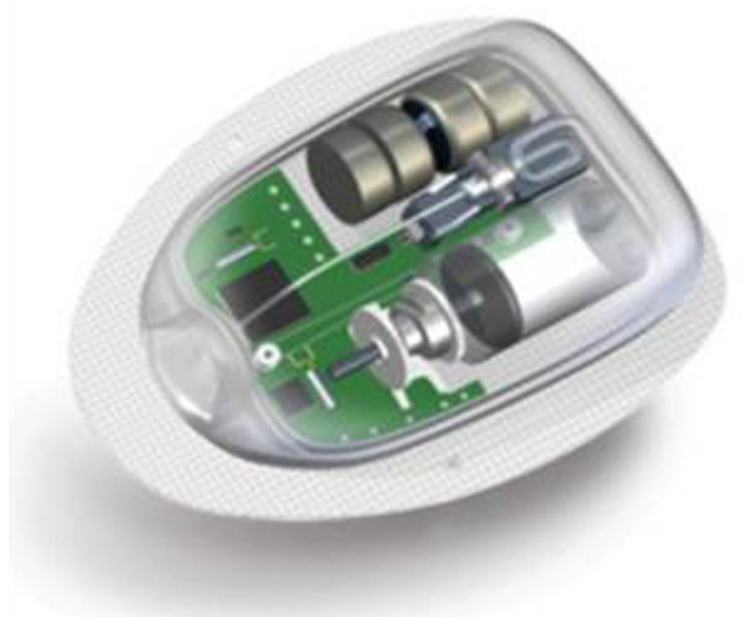

a motion sensor. The SMA wire assembly rotates the driveshaft/leadscrew, advances the piston within the reservoir, and delivers insulin through the cannula. Each actuation of the motor mechanism delivers 0.05 units of insulin.

\section{Pod Insulin Reservoir}

The Pod incorporates a fully integrated insulin reservoir that holds up to 200 deliverable units of U-100 insulin (Figure 3). It requires no separate administration sets or reservoirs.

\section{Fill Process}

Each Pod is supplied with a fill syringe and a fill needle that are used to introduce insulin into the Pod. The fill syringe is sized to match the maximum fluid volume of the Pod with a self-stopping plunger rod that limits the amount of insulin it can contain. The syringe is clearly marked with the minimum fill volume (85 units) of the Pod and in units of insulin.

After the patient fills the syringe with insulin, s/he injects it into the Pod reservoir through the fill port on the bottom of the Pod. The selfsealing fill septum is designed for single use only. 
Figure 4. Catheter view demonstrating 45-degree angle and $6.5 \mathrm{~mm}$ vertical depth.

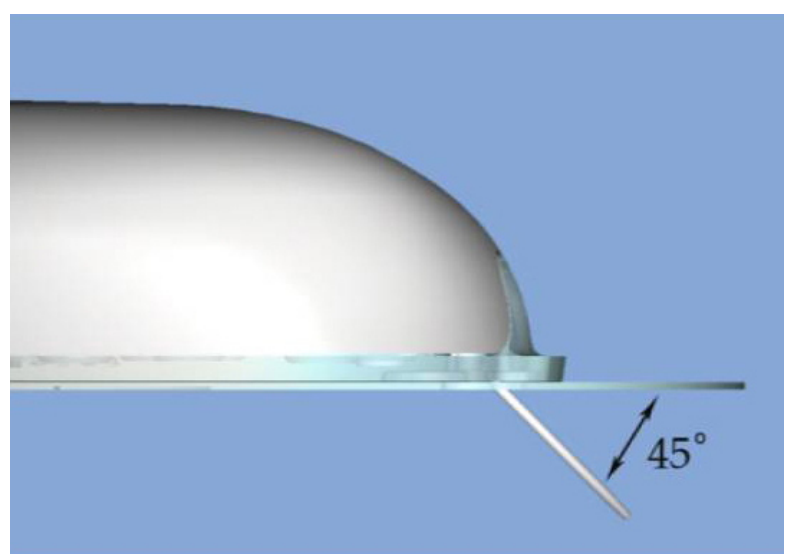

It is located on the bottom (skin contacting) surface of the Pod to eliminate the possibility of injecting insulin into the port for a second use. Typical pod wear times vary from 48 to 72 hours. The pod has the capability of lasting up to 80 hours to allow for flexibility in changing the pod due to unforeseen circumstances.

\section{Cannula Insertion Process}

When the patient is ready to attach the Pod, $\mathrm{s} /$ he removes the adhesive and needle cover from the back and sticks the Pod onto the prepared site. By following the PDM's screens and pressing specific buttons, the patient tells the Pod to activate its insertion mechanism, which quickly drives both the insertion needle and the soft cannula into the subcutaneous tissue. The insertion needle punctures the skin and stiffens the cannula during the insertion process. When it reaches its forward limit of travel, the insertion mechanism retracts and withdraws only the needle, leaving the cannula in place at the infusion site. The actual insertion takes only five 1000ths of a second. The Pod places the soft cannula into the patient's tissue at a 45-degree angle, to a depth of $6.5 \mathrm{~mm}$ (Figure 4 ). The adhesive pad on the base holds the Pod and the cannula in place.

\section{Insulin Delivery}

The PDM handles all processes for the operation of the system. The display uses full text to prompt the user through the set-up and use processes. The patient must use the PDM to program the Pod with the his/her custom basal profile, check the Pod status, initiate a bolus, or make changes to the insulin delivery profile. The PDM needs to be within $60 \mathrm{~cm}$ to communicate with the Pod to perform these tasks. After set-up and initiation, the Pod runs at the programmed basal rate independently of the PDM. If the PDM requires the patient's attention, the Pod sounds an alarm beeper.

\section{Incorporated BG Measurement}

The PDM incorporates a FreeStyle (Abbott Diabetes Care) BG monitor. The BG data is stored and its history can be displayed on the PDM. For example, a patient's BG variations can be seen in both graphical and list form for the past $1,7,14,30,60$, and 90 days. The list form shows, for each time period, the average number of readings taken, the average BG, the minimum and maximum readings, the patient's BG goal range, and the percentage of readings within, above, and below that goal. Along with insulin delivery records, this information can be quite valuable to the physician or nurse when reviewing the patient's status.

\section{Suggested Bolus Calculation}

The PDM provides the ability to calculate a suggested bolus dosage, which has traditionally been done manually by MDI users. Similar convenience features have since been incorporated into traditional CSII pumps. The suggested bolus calculation feature is provided as a convenience to the user to aid in determining the bolus dosage needed based on carbohydrates ingested, most recent BG reading, user-settable correction factor, insulin- 
Table 3. Results of clinical trials and reviews involving the OmniPod Insulin Management System.

\begin{tabular}{|c|c|}
\hline Clinical trial report & Results \\
\hline $\begin{array}{l}\text { OmniPod Insulin Management System: patient } \\
\text { perceptions, preference, and glycemic control } \\
\text { Howard Zisser and Lois Jovanovič }(2006)^{1} \\
\text { - } 20 \text { patients currently using CSII switched } \\
\text { to OmniPod System for } 30 \text { days. } \\
\text { - All patients completed exit questionnaire } \\
\text { comparing using the OmniPod System with } \\
\text { using their current insulin pump. }\end{array}$ & $\begin{array}{l}\text { - } 90 \%(18 \text { of } 20) \text { preferred using the OmniPod automated cannula } \\
\text { insertion system vs. their current infusion sets. } \\
\text { - } 11 \mathrm{C} \text { values decreased from mean of } 7.1 \% \text { to mean of } 6.8 \% \\
(P<0.002) \text {. } \\
\text { - Mean responses, on a scale from } 1 \text { to } 5 \text {, where } 1=\text { most favorable } \\
\text { and } 5=\text { least favorable, were: } \\
\text { Convenience of use }=1.85 \\
\text { Satisfaction with wearing OmniPod }=1.7 \\
\text { Satisfaction with current insulin pump }=1.9 \\
\text { Pain associated with automated cannula insertion }=2.0 \\
\text { Wearing while sleeping }=1.15 \\
\text { Wearing while showering }=1.1 \\
\text { Time involved in Pod change process }=2.05\end{array}$ \\
\hline
\end{tabular}

Quantifying the impact of a short-interval interruption of insulin-pump infusion sets on glycemic excursions Howard Zisser $(2008)^{2}$

- Studied the effect on blood glucose of short interruptions of basal insulin delivery.

Siphon effects on continuous subcutaneous insulin infusion pump delivery performance

Howard Zisser et al. $(2010)^{3}$

- Studied the effect of changing the position of traditional insulin pumps in relation to the position of the cannula on insulin delivery accuracy.

Clinical experience with a tubing-free insulin pump system

Michael Kane et al. (2009) ${ }^{4}$

- Retrospective study of patients who had begun using the OmniPod System 1 year prior.

- Of 59 patients, 47 had used MDI, 12 had used different brand of pump.

An innovative application of shape memory alloy (SMA) technology yields a novel therapeutic approach to diabetes management

Steve Dilanni and John Garibotto (2006)

- Technical paper on the enabling technology for the development of the OmniPod System.
- Blood glucose levels rose $1 \mathrm{mg} / \mathrm{dL}$ for each minute insulin infusion was interrupted.

- A 30-minute interruption in basal insulin infusion resulted in a rise of $30 \mathrm{mg} / \mathrm{dL} 3$ hours after reconnecting the insulin pump.

- Traditional pumps with cannulas showed significant changes in insulin delivery, ranging from $74.5 \%$ of expected delivery when pumping towards a site above the pump, to $123.3 \%$ when pumping downward, at a $1 \mathrm{U} /$ hour rate.

- The OmniPod System performed with minimal variation in insulin delivery, from $99 \%$ of expected delivery when pumping upward to $101 \%$ when pumping downward at the same $1 \mathrm{U} /$ hour rate.

- Average A1C values decreased a significant $0.49 \%(P<0.01)$.

- $25.5 \%$ of patients obtained A1C value of $<7 \%$ after 1 year using OmniPod System; only $5.7 \%$ of patients had obtained that value prior to using it.

- Reduction of DKA episodes (1 vs. 3).

- Acceptance rate for the OmniPod was $92.2 \%$.

- SMA technology applied to the motor of the Pod enables improved reliability, a more compact system, reduced cost, and reduced weight.

- SMA wire-actuated motor is unable to "run away" when power is applied directly, eliminating electromechanical failure and increasing accuracy and safety. 
Table 3. (Continued)

\begin{tabular}{ll}
\hline Clinical trial report & Results \\
\hline $\begin{array}{l}\text { Computer-aided learning in insulin pump training } \\
\text { Sergey Sirotinin and Charles George }(2010)^{6}\end{array}$ & $\begin{array}{l}\text { All trainers agreed the OmniPod training CD helped patients new } \\
\text { to insulin pump therapy gain a positive attitude toward it. }\end{array}$ \\
$\begin{array}{l}\text { - Study of acceptability of OmniPod interactive } \\
\text { training tool to healthcare professionals }\end{array}$ & $\begin{array}{l}\text { - } \\
\text { experienced in diabetes education and certified }\end{array}$ \\
$\quad \begin{array}{l}\text { in pump training. } \\
\text { - Over a 3-month period, } 126 \text { trainers trained }\end{array}$ \\
$\begin{array}{l}\text { 1244 patients on four different brands of insulin } \\
\text { pump. }\end{array}$
\end{tabular}

A prospective trial of $U-500$ insulin delivered by

OmniPod in patients with type 2 diabetes and

severe insulin resistance

Wendy Lane et al. $(2010)^{7}$

- One-year study tested efficacy and safety of U-500 insulin delivery via the OmniPod System

to patients with uncontrolled type 2 diabetes and severe insulin resistance.

In silico evaluation platform for artificial pancreatic beta-cell development-a dynamic simulator for closed-loop control with hardware-in-the-loop* Eyal Dassau et al. (2009) $)^{8}$
- Significant reduction in A1C of $1.23 \%(P=0.0008)$.

- Significant increase in percent of time spent within target blood glucose range, 70 to $180 \mathrm{mg} / \mathrm{dL}: 70.75 \%(P=0.0001)$.

- 14 of 20 subjects elected to remain on OmniPod at study completion.

- Testing of artificial beta-cell systems on computers usually involves only the controller software; this development enables testing of hardware as well.

Closed-loop artificial pancreas using subcutaneous glucose sensing and insulin delivery and a model predictive control algorithm: preliminary studies in Padova and Montpellier*

Daniela Bruttomesso et al. (2009) ${ }^{9}$

Closed-loop artificial pancreas using subcutaneous glucose sensing and insulin delivery and a model predictive control algorithm: the Virginia experience* William Clarke et al. (2009) ${ }^{10}$
- Allows full-system verification and validation, including hardware limitations.

- Allows systematic analysis of monitoring and control algorithms.

- Streamlines preclinical validation trials.

*Study funded in part by the Juvenile Diabetes Research Foundation's Artificial Pancreas Project.

$\mathrm{CSII}=$ continuous subcutaneous insulin infusion; $\mathrm{DKA}=$ diabetic ketoacidosis; $\mathrm{MDI}=$ multiple daily injections. 
to-carbohydrate ratio, target BG value, and duration of insulin action.

\section{DOES THE OMNIPOD SYSTEM PROMOTE BETTER TYPE 1 DIABETES MANAGEMENT?}

CSII delivery, in general, allows for greater flexibility in insulin delivery options leading to more lifestyle choices related to meal planning and exercise. More specifically, I believe the use of the OmniPod System contributes to improved diabetes management for a variety of reasons, including ease of training, setup and insertion, uninterrupted and untethered insulin delivery, and inclusion of a glucose meter in the PDM. An additional advantage of the System may be that the Pod, once on the body, does not move around much. This results in less fluctuation in hydrostatic pressures, ideally leading to more consistent insulin delivery. In the near future, Insulet Corporation will release in the US a modified PDM that receives continuous glucose sensing data from the iDex platform (DexCom, Inc., San Diego, CA, USA).

In 2005, Dr. Lois Jovanovič and I performed the first clinical evaluation of the OmniPod System in 20 subjects with type 1 diabetes. ${ }^{1}$ (See also Table 3 for brief summaries of studies. ${ }^{1-10}$ ) This 30-day study, supported by a grant from Insulet, assessed the comfort, function, and use of the System compared with conventional insulin pumps. The trial was designed to see how the subjects liked the new pump compared to their current, traditional CSII pump. We found that the subjects much preferred wearing the OmniPod System. Ninety percent of subjects (18 of 20) preferred using the OmniPod automated cannula insertion system versus inserting with their current infusion sets. What we didn't expect from a month-long pilot study was that the vast majority of the subjects had $\mathrm{A} 1 \mathrm{C}$ values at the end that were significantly lower, dropping from a mean of $7.1 \%$ (range 5.5-8.1) to a mean of $6.8 \%$ (range $5.4-7.6 ; P<0.002$ ). This significant change was even more surprising because I had not changed the subjects' pump settings when starting them on the OmniPod System.

We expected some "study effect" on the subjects' A1C values but we did not expect that large a decrease in such a short time. What could be responsible for this improved control despite staying on the same pump settings as their traditional pump? In a later study, I discovered the likely answer to that question. ${ }^{2}$ One obvious difference was that the subjects wearing the OmniPod System never disconnected from their pump for any reason other than putting on a new Pod when the insulin ran out. CSII therapy allows for uninterrupted, around-theclock delivery of insulin, but in practice, many patients disconnect their insulin pumps from their infusion sets when showering, changing clothes, swimming, exercising, or during intimate moments. Ranging in time from a few minutes to several hours, these periods of interrupted insulin infusion result in the cessation of basal insulin delivery. Interrupting insulin delivery may be appropriate during periods of exercise when insulin sensitivity increases or during hypoglycemia; however, cessation of insulin delivery may be detrimental even for short periods, especially if it occurs when insulin resistance is at its peak. A prospective, openlabel study was designed to measure the impact of short-term infusion-set disconnects and infusion-set changes on glucose levels.

Nineteen subjects with type 1 diabetes were studied on two separate in-clinic days. ${ }^{2}$ One hour after arriving at the clinic in a fasting state, subjects either temporarily disconnected their infusion sets from their pumps, interrupting basal insulin infusion for 30 minutes, or, on a separate day, changed their infusion sets. 


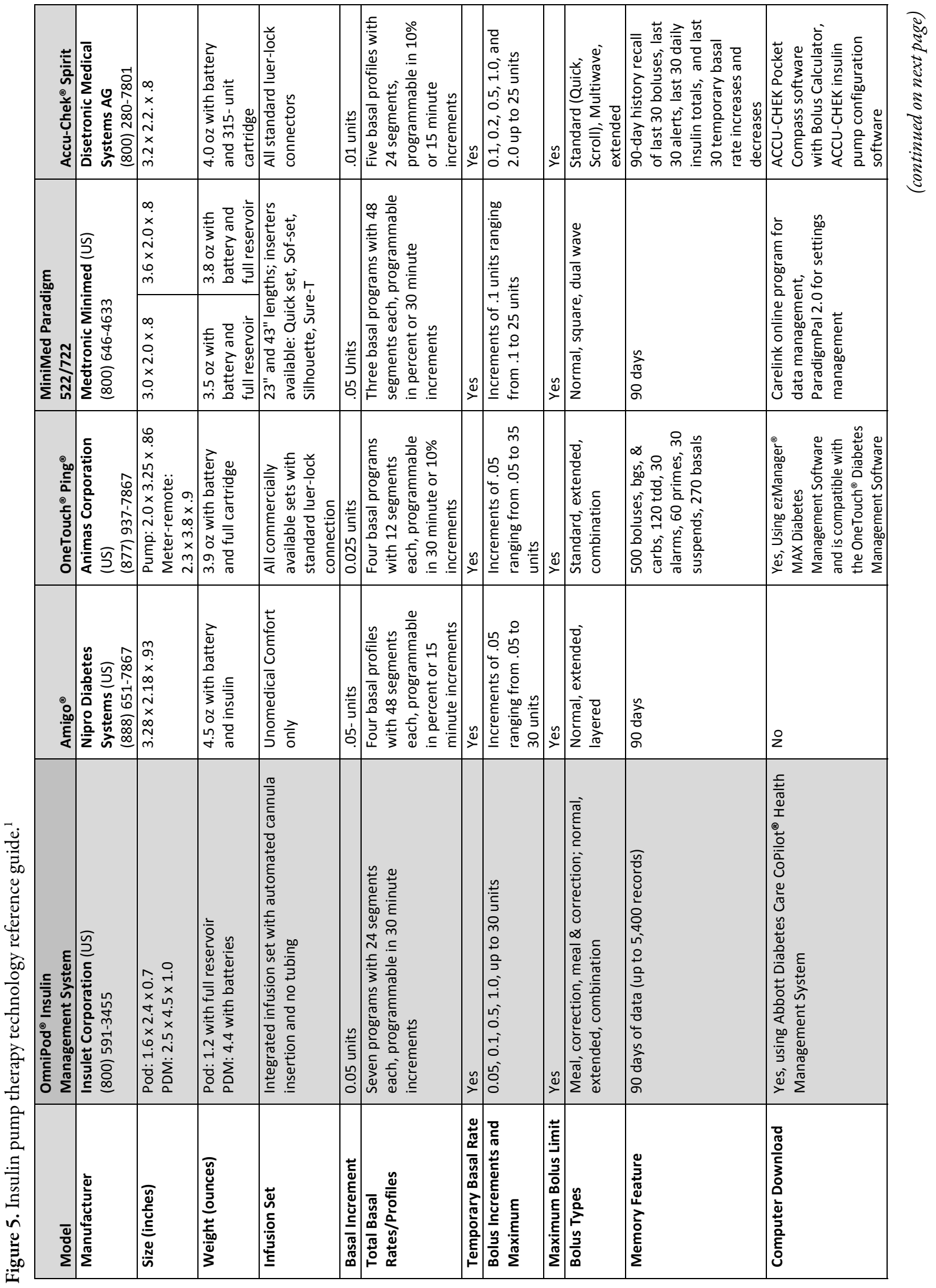







Glucose levels were monitored for an additional 4 hours on both occasions. Changing infusion sets did not affect short-term glucose control. However, the 30-minute interruption of basal insulin infusion resulted in significant glucose elevation: $1 \mathrm{mg} / \mathrm{dL}$ for each minute basal insulin infusion was interrupted.

A second, less obvious difference between a traditional CSII pump and the OmniPod System is that a traditional pump is tethered to the body and therefore moves around in relation to the insulin infusion site. Could this movement result in changes in insulin delivery? A bench-top study was designed to quantify these hydrostatic effects on CSII pumps during basal and bolus insulin delivery. ${ }^{3}$ We tested CSII pumps from Medtronic Diabetes (MiniMed 512 and 515), Smiths Medical (Deltec Cozmo 1700), and Insulet (OmniPod) using insulin aspart (NovoLog, Novo Nordisk).The pumps were filled and primed per manufacturer's instructions. The fluid level change was measured using an inline graduated glass pipette (100 microliters) when the pipette was moved in relation to the pump (80 cm Cosmo and $110 \mathrm{~cm}$ Medtronics) and when level. Pumps were compared during 1 and $5 \mathrm{U}$ boluses and basal insulin delivery of 1.0 and $1.5 \mathrm{U} /$ hour. We found pronounced differences that were seen during basal delivery in pumps using 80-100 $\mathrm{cm}$ tubing. For the $1 \mathrm{U} /$ hour rate, differences ranged from $74.5 \%$ of the expected delivery when the pumps were below the pipettes and pumping upward, to $123.3 \%$ when the pumps were above the pipettes and pumping downward. For the $1.5 \mathrm{U} /$ hour rate, differences ranged from $86.7 \%$ to $117.0 \%$ when the pumps were below or above the pipettes, respectively. Compared to pumps with tubing, the OmniPod System performed with significantly less variation in insulin delivery. Changing position of a conventional CSII pump in relation to its tubing results in significant changes in insulin delivery. The siphon effect in the tubing may affect the accuracy of insulin delivery, especially during low basal rates. This effect has been reported when syringe pumps were moved in relation to infusion sites but had not been reported with CSII pumps. Please note that this was a bench-top laboratory evaluation without clinical validation. (While the specific MiniMed and Deltec pumps used in this study are no longer being sold, presumably the same siphon effect applies with newer pumps that use similar tubing.)

Additional clinical differences may exist than those given above. More research may be needed to quantify those clinical differences between traditionally designed insulin pumps and this new category of pump.

\section{REVIEW OF CLINICAL DATA}

\section{Clinical Trials and Reviews}

Clinical trials like those referred to above have demonstrated the effectiveness of Insulet's OmniPod Insulin Management System in managing diabetes. Table 3 lists these and a number of other trials and published research papers related to the OmniPod System. ${ }^{1-10}$

\section{Ongoing Research and Development}

The OmniPod System is currently in use as part of the Juvenile Diabetes Research Foundation's (JDRF) Artificial Pancreas Project (APP). This is a global initiative to develop a firstgeneration artificial-pancreas therapy model. It integrates a continuous BG monitor and an insulin pump, with a customized algorithm, to deliver the appropriate dose of insulin. Starting approximately 3 years ago, the OmniPod System continues to be used at the majority of the JDRFfunded clinical research sites worldwide. The 
Table 4. Common patient questions about the OmniPod Insulin Management System.

\begin{tabular}{ll}
\hline Question & Answer \\
$\begin{array}{l}\text { Is the OmniPod System approved } \\
\text { for everyone-even children and } \\
\text { teens? }\end{array}$ & $\begin{array}{l}\text { Yes, the OmniPod is approved for people of all ages who have diabetes and use insulin-including } \\
\text { children and teens. }\end{array}$ \\
\hline $\begin{array}{l}\text { Can I swim with the OmniPod } \\
\text { System? }\end{array}$ & $\begin{array}{l}\text { The watertight Pod can go in the pool, the ocean, the shower, or the tub for up to } 7.6 \text { meters (25 feet) } \\
\text { for } 60 \text { minutes with no need to disrupt insulin delivery. The PDM, though, is not waterproof. }\end{array}$ \\
\hline $\begin{array}{ll}\text { Does the OmniPod System } \\
\text { provide data download capability? }\end{array}$ & $\begin{array}{l}\text { In the US, the OmniPod System downloads insulin delivery, BG, and carbohydrate records to the } \\
\text { CoPilot }{ }^{\circledR} \text { Health Management System, enabling the user to create customized reports, charts, and }\end{array}$ \\
\hline $\begin{array}{l}\text { Can I travel while using the } \\
\text { OmniPod System? }\end{array}$ & $\begin{array}{l}\text { Yes. Contact your airline for information on current security requirements. The PDM and Pods can } \\
\text { safely pass through airport } \mathrm{x} \text {-ray machines. If the security detector goes off, tell the security screener } \\
\text { that you have diabetes and wear an insulin Pod. }\end{array}$
\end{tabular}
\begin{tabular}{ll}
\hline Can I play sports while wearing & Yes. You can play sports and participate in physical activities while wearing a Pod-just leave the PDM \\
a Pod? & in your gym bag.
\end{tabular}
How close do the OmniPod For programming insulin delivery or responding to Pod alarms or alerts, the PDM and Pod need to and the PDM need to be to be within $61 \mathrm{~cm}$ of each other. Otherwise, they do not need to be near each other at all. The Pod will communicate with each other? continue to deliver your current background (or basal) insulin, even if your PDM is not nearby.

What type of insulin should I use The Pod is designed to be used with U-100 rapid-acting insulin. The following U-100 rapid-acting with the Pod? insulin analogs have been tested and found to be safe for use in the Pod: NovoLog ${ }^{\circledR}, \operatorname{NovoRapid}^{\circledR}$, Humalog ${ }^{\circledR}$, or Apidra ${ }^{\circledR}$. Before using different insulin with the OmniPod System, check the insulin drug label to make sure it can be used with a pump and consult with your healthcare professional.

\section{How much insulin does the Pod The Pod holds up to 200 units of insulin; it requires a minimum of 85 units of insulin to begin} hold? operation.

What type of adhesive does the Pod use? The Pod uses an adhesive similar to the adhesive used with common infusion sets. The adhesive is latex-free, acrylic-based, and ideal for holding the Pod, even in the presence of moisture. It is designed to hold the Pod securely in place for the duration of wear.

Where on my body can I wear the Pod?

The Pod's automated cannula insertion enables you to wear it many places. It is recommended that you begin on your abdomen, because it is easy to access and see what you're doing. Once you have mastered using the Pod, however, you can wear it on your leg, upper thigh, lower back, or the back of your upper arm-in fact, anywhere you would give yourself an injection. Of course, you want to avoid wearing the Pod within 2 inches of your navel and in other areas where belts, waistbands, or tight clothing may rub against, disturb, or dislodge it.

How long do I wear each Pod? A Pod expires 72 hours after activation. You should refer to the insulin labeling and follow your healthcare provider's directions concerning when to replace the Pod.

How long do the batteries last in The PDM batteries last approximately 3 weeks. Extensive use of the bright-mode option may shorten the PDM? this time frame.

What if I leave home without my Your Pod will continue to deliver your current background (or basal) insulin, even if you do not have PDM or leave it somewhere? your PDM with you. However, you will not be able to make changes to your basal delivery, deliver bolus doses, test your BG, or respond to alarms or alerts when your PDM is not with you.

What happens if I lose my PDM? Our experience has been that very few people lose their PDM. However, if you do, please contact Insulet Corporation immediately for a replacement. In most cases, you will receive your replacement within 24 hours. Of course, some people like to order a back-up PDM to have on hand just in case.

$\mathrm{BG}=$ blood glucose; $\mathrm{PDM}=$ personal diabetes manager. 
OmniPod System is also scheduled to be used at a number of EU sites as part of the AP@home Artificial Pancreas Project. ${ }^{11}$

\section{COMPARISON WITH OTHER INSULIN PUMPS}

Figure 5 provides a comparison of the Insulet OmniPod System to four traditionally designed insulin pumps. Notice especially the list of additional features at the end of the table. These include the OmniPod System's tubing-free design, innovative safety features, integrated bolus calculator, and many personalized settings.

The OmniPod System may have limitations for some users:

- Occasional Pod failure does occur. This may be due to inserting the Pod in a site with scar tissue, system failure, occlusion, or some other cause.

- In extreme heat, the Pod's adhesive may not hold securely. As with traditional infusion sets, the patient may have to add extra adhesive.

- Some patients are especially self-conscious and may not want a "bump" on their bodies. They may feel they can hide a conventional pump more easily, even with tubing and the bulk of the pump itself.

- Patients who require more than 100 units of insulin per day may do better choosing a pump with a larger, 300-unit reservoir. Some may be able to change the Pod every 2 days instead of every 3 days.

\section{PATIENT CONCERNS}

Patients with diabetes will have concerns about using a new device. Table 4 shows the answers to some of the most common questions patients have. A broader range of questions and answers is available online. ${ }^{12}$

\section{CONCLUSION}

For many patients with diabetes, CSII is the only way to reach acceptable glucose control levels. The OmniPod Insulin Management System improves on the traditional method of delivering insulin via CSII for the following reasons:

- It frees patients with diabetes of being tethered to their pumps.

- It provides consistent, round-the-clock, uninterrupted insulin delivery.

- It allows for easier set up and automated cannula insertion.

- Greater convenience often leads to better compliance.

The OmniPod System offers the comfort and safety of feedback and alarms, the ability to follow daily, monthly, and quarterly progress, and the feeling of accomplishment in managing one's own diabetes. Additionally, patients do not need to be technologically "savvy," because the device's user interface is very clear and straightforward. Almost all patients with type 1 diabetes can benefit from using the OmniPod System.

Several next-generation systems are rumored to be in development at Insulet Corporation. These systems include a PDM that receives continuous glucose monitor (CGM) data from the DEXCOM 7 Plus continuous glucose sensor, a Pod that is over a third smaller in size with the same technical features, a Pod that incorporates a CGM sensor, and a Pod that has the ability to deliver multiple compounds.

The OmniPod platform lends itself to many other uses. It is presently being used in Europe by Ferring Corporation as a delivery mechanism for an infertility drug. Other potential applications include: pain management; chemotherapeutic agents; AIDS, Parkinson's, and multiple sclerosis drugs; biologics; thyroid, 
growth hormones, and related peptides; as well as in-hospital uses.

\section{ACKNOWLEDGMENTS}

The author thanks Insulet Corporation for providing technical support for this article and for permission to use the photographs.

The author has the following disclosures: Consultant Advisor: Animas, Insulet, MannKind, and Roche. Research Support: DexCom, Eli Lilly, GluMetrics, Insulet, LifeScan, Medtronic, and Roche.

Cynthia M. Shaler provided editorial assistance in preparing this manuscript. Ms. Shaler is a technical and medical designer, editor, and writer.

Prior to peer review, the manufacturers of the OmniPod Insulin Management System, Insulet and Ypsomed, were offered the opportunity to review the article solely to ensure accuracy of the data. Minor changes were made to the content as a result.

Open Access. This article is distributed under the terms of the Creative Commons Attribution Noncommercial License which permits any noncommercial use, distribution, and reproduction in any medium, provided the original author(s) and source are credited.

\section{REFERENCES}

1. Zisser HC, Jovanovič L. OmniPod Insulin Management System: patient perceptions, preference, and glycemic control. Diabetes Care. 2006;29:2175. Letter.

2. Zisser HC. Quantifying the impact of a shortinterval interruption of insulin-pump infusion sets on glycemic excursions. Diabetes Care. 2008;31: 238-239.
3. Zisser HC, Bevier W, Dassau E, Jovanovič L. Siphon effects on continuous subcutaneous insulin infusion pump delivery performance. J Diabetes Sci Technnol. 2010;4:98-103.

4. Kane MP, Abelseth JM, Davis K, Hogan E, Hamilton RA. Clinical experience with a tubingfree insulin pump system. Infusystems USA. 2009; 6:25-27.

5. Dilanni S, Garibotto J. An innovative application of shape memory alloy (SMA) technology yields a novel therapeutic approach to diabetes management. Insulet Corporation. 2006:12028AW. Rev 2/04/09.

6. Sirotinin S, George C. Computer-aided learning in insulin pump training. J Diabetes Sci Technnol. 2010;4:1022-1026.

7. Lane W, Weinrib SL, Rappaport JM, Przestrzelski T. A prospective trial of U-500 insulin delivered by OmniPod in patients with type 2 diabetes and severe insulin resistance. Endocr Pract. 2010. In press.

8. Dassau E, Palerm CC, Zisser H, Buckingham BA, Jovanovic L, Doyle FJ. In silico evaluation platform for artificial pancreatic beta-cell development-a dynamic simulator for closed-loop control with hardware-in-the-loop. Diabetes Technol Ther. 2009;11:187-194.

9. Bruttomesso D, Farret A, Silvana C, et al. Closedloop artificial pancreas using subcutaneous glucose sensing and insulin delivery and a model predictive control algorithm: preliminary studies in Padova and Montpellier. J Diabetes Sci Technnol. 2009;3:1014-1021.

10. Clarke WL, Anderson S, Breton M, Patek S, Kashmer L, Kovatchev B. Closed-loop artificial pancreas using subcutaneous glucose sensing and insulin delivery and a model predictive control algorithm: the Virginia experience. J Diabetes Sci Technnol. 2009;3:1031-1038.

11. AP@Home - bringing the artificial pancreas home. Available at: www.apathome.eu. Accessed August 10, 2010.

12. OmniPod Insulin Management System. Available at: www.myomnipod.com/about-omnipod/faqs. Accessed August 10, 2010. 